This is a pre-copyedited, author-produced PDF of an article accepted for publication in Policing following peer review. The version of record Aisha K. Gill, Karen Harrison; Police Responses to Intimate Partner Sexual Violence in South Asian Communities, Policing: A Journal of Policy and Practice, Volume 10, Issue 4, 1 December 2016, Pages 446-455 is available online at: https://doi.org/10.1093/ police/paw027

\title{
Police responses to intimate partner sexual violence in South Asian communities Aisha K. Gill ${ }^{1}$ and Karen Harrison ${ }^{2}$
}

\begin{abstract}
Recognition of sexual violence as a serious problem has been reflected in the wide range of initiatives that over the past 20 years in the United Kingdom have been designed to tackle this problem. Emphasis on prevention, protection and redress has enabled criminal justice and other responses to become increasingly embedded. Nevertheless, a significant lacuna remains in terms of the contours, context, and consequences of intimate partner sexual violence in South Asian communities. Despite victim-survivors' offering solid evidence of the prevalence of sexual violence in these communities, this kind of abuse is generally not reported to criminal justice agencies (Gilligan and Akhtar, 2006; Hohl and Stanko, 2015). Anecdotally, however, this type of violence does appear to have been increasing over time. With that backdrop in mind, this article looks at how four police areas are currently responding to intimate partner sexual violence where the victim-survivor of it is from a South Asian community. In particular, the article evaluates police officers' levels of understanding with regard to pertinent cultural values and, in turn, assesses the level of training given to help with this awareness, and the appropriateness of front-line police practice. Finally, consideration is also given to what needs to change in order to encourage more victimsurvivors from South Asian communities to come forward.
\end{abstract}

\section{Violence against women in BME communities: intersectionality ${ }^{1}$ and intersectional discrimination}

While some recent critics of feminism have characterised the concept of 'intersectionality'as a theoretical privilege reserved for those with power, feminism has always recognised the role of the various forms of power and, above all, the interplay between these different forms. Discourses on gender often contain inherent notions of heteronormativity. Socio-economic status is seen as both a source for the oppression of women and a privilege reserved for certain women at the expense of others. Equally important are 'race' and nationality and how these affect the experience of oppression and inequality, both within and between different

\footnotetext{
${ }^{1}$ Professor of Criminology, University of Roehampton, UK

${ }^{2}$ Senior Lecturer, School of Law, University of Hull UK
} 
groups. Issues that disproportionately affect black, minority ethnic and refugee women and girls are often treated as separate from the issue of violence against women in general. Furthermore, there are particular groups of women and girls who are often overlooked in terms of policymaking, and about whom there is insufficient information and data. Neglect of these issues applies particularly to black and minority ethnic women (BME) ${ }^{2}$, women with mental health needs, women with insecure immigration status, older women, women with disabilities (including learning disabilities), and girls who are within or looked after by institutions (Jones, 2015). Walby, Armstrong and Strid (2012) draw attention to how systems of social relations are altered, but not completely transformed, at points of intersection. Importantly, Crenshaw (1992) maintains that experiences of violence and victimisation are configured differently at various intersections of 'race', class, gender, age and sexuality. Additionally, Walby and Allen (2004) claim that the impact of domestic violence and abuse on heterosexual men, for instance, may be less severe than on heterosexual women. The experience of lesbians living in abusive relationships, on the other hand, may be more heterogeneous than that of heterosexual women (Donavan and Hester, 2014). Further examples of the importance of intersectionality and the positionality of the victims-survivors of gender-based violence are also to be found in religiously-defined communities; for example, some lesbian and gay Sikhs and Muslims are forced by their communities to marry, regardless of their sexual orientation (Hester et al., 2012).

Although we do already have an established knowledge base regarding the issue of domestic violence as it affects black and minority ethnic women, this body of research has focused largely on particular groups within this broader sector. It is, therefore, important to note here that BME women are especially located at the intersection between numerous structural inequalities and, as a result, face intersectional discrimination. In such a situation, the available research has repeatedly shown that BME women who experience domestic violence face additional issues and pressures on top of those affecting victim-survivors per se, thereby compounding their situation (Anitha, 2008). While BME women are equally as likely as others to become victims, it is becoming clear that important differences exist between the two groups (i.e. BME victims and other female victims) and also that these differences influence both the responses of BME women and the ways in which they are treated by the service providers. 
Experiences of domestic violence are often more complex for BME women and children than for other groups, because they are more likely to suffer abuse, not only from their partners and fathers but also from multiple family members (Thiara, 2005). Cultural beliefs such as izzat and sharam (honour/reputation) can control women's behaviour and constrict their choices, especially around help-seeking (Izzidien, 2008). Research on BME women and children facing domestic violence highlights inappropriate professional responses from statutory and voluntary services as a common experience; for South Asian victim-survivors this is particularly the case. Furthermore, Izzidien (2008) indicates that agencies and professionals are reluctant to engage in this area for fear of appearing to be racist (Izzidien, 2008). For some time, concern about a lack of co-ordination and the need for better multiagency work in responding to South Asian families has also been highlighted, as have high levels of stereotyping and racism. Indeed, the social care literature has revealed the pathologising of black families by professionals who tend to misunderstand or essentialise cultural specificities (Bhatti-Sinclair, 2011; Brah and Phoenix, 2013). The use of 'culture' to explain problems in service delivery is reported to be widespread, with professionals' inadequate understanding of cultural specificities often seen to act as an obstacle in providing effective responses to, for instance, South Asian families (Bhatti-Sinclair, 2011). Research has also pointed to the limitations of using 'culture' as a concept to assess risk and needs and has underlined the inadequacy of using 'culture' to frame appropriate responses. Instead, studies such as Quereshi, Berridge and Wenman, (2000) emphasise the heterogeneity of communities and make clear that "the cultural context of two families living as neighbours, even if from the same religious and ethnic background is unlikely to be identical and that explaining issues solely in terms of culture, though relevant, is inadequate in supporting individual families” (Quereshi et al., 2000:59). How criminal justice agencies and - for this article in particular - the police respond to intimate partner sexual violence is, therefore, key not just in terms of securing criminal convictions, but, more importantly, in terms of supporting and protecting victim-survivors.

\section{Background and methodology}

The data used in this article was collected as part of a larger qualitative project which was funded by the British Academy ${ }^{3}$ exploring the barriers preventing women and children from South Asian communities, living in England and Wales, from reporting sexual abuse. The data collection took place during the period May 2013 to June 2015. In order to garner as 
many viewpoints as possible, the researchers held four focus groups, speaking with approximately 85 women who were living in South Asian communities in England at the time. These groups were not set up for the sole purpose of the research, but were groups of women who met regularly and who agreed to speak to us. Not everybody in each group spoke out; but, as the subject matter being covered was extremely sensitive, this silence was understandable. The sensitivity of the subject matter also justified the use of larger than normal groups. Participants were not directly asked if they themselves had been victims of sexual abuse; however, through listening to their responses, it was clear that several of them had indeed been abused and these women spoke at length about their experiences. Thirteen victims of sexual abuse were also interviewed, as were representatives from 13 women's nongovernmental organisations (NGOs). For the purpose of this research, the term 'South Asian' refers to (i) people born in the Asian sub-continent (i.e. India, Pakistan and Bangladesh) and (ii) people of South Asian heritage born in Britain.

In terms of the data collected from the police, nine officers from four police areas with relatively high South Asian populations were interviewed. To supplement their responses, the authors also talked to a Chief Prosecutor, to a high ranking civil servant with responsibility for protecting vulnerable adults and children in one of these areas, and to a policy officer. It is acknowledged that interviewing 12 people about this topic cannot be considered as fully representative of opinion from criminal justice and governmental agencies. What is offered here should, therefore, be considered as a snapshot of views taken during a specific time period. For reasons of confidentiality, exact police areas have not been reported. To help retain anonymity, no police ranks are mentioned and all officers are referred to as 'he' regardless of actual gender.

\section{Women's perceptions of the police}

The main purpose of the empirical study upon which the current article is based was to discover why women and children from South Asian communities do not tend to report sexual abuse. It was important to undertake such a study because there is a perception that this particular community significantly underreports this type of violence. The first aim of the research was, therefore, to establish whether or not this supposition was in fact true. This task was fairly difficult, because neither the police nor the Crown Prosecution Service (CPS) collects data on a victim's ethnic background; nevertheless, the starting hypothesis was 
confirmed by both the women and police who participated in the study. For example, police officers' remarks included: "We get very little reporting within domestic relationships . . . It's negligible really from Pakistani, Bangladeshi and also from Indian communities”, and "We've always had underreporting from the South Asian community.” One of the reasons the women from the focus groups gave for this underreporting was that it stemmed from how they viewed the police and what they thought the police's response to such complaints would be. They argued that the police were all men who did not understand their cultural needs. The women also voiced their concerns that the police would side with men (i.e. their husbands and other patriarchal figures in the family). They feared that their stories would not be believed, or that, even if they were believed, no action would ultimately be taken against their abusers. One of the aims of this article is, therefore, to compare these perceptions with practice and to evaluate the representation of a typical police response to intimate partner sexual violence in South Asian communities.

\section{Perceptions versus actual practice}

\section{Police are all men}

A very common viewpoint presented by the women in the focus groups was that the police would all be men. However, while the number of women employed as police officers in the police does not mirror the make-up of the population of England and Wales, it is certainly not true to say that all police are male. On 31 March 2015, there were 207,140 police workers in the 43 police force areas, 91.6 per cent of whom were front-line officers. Of these, 28.2 per cent were female. Of interest also for this article is that 5.5 per cent of these front-line officers were from minority ethnic backgrounds (Home Office 2015). The reality is, therefore, that, while the majority of police officers are white males, that profile does not represent the whole force. Indeed, many of the participant officers explained how a complainant's request to speak to a female officer could be facilitated, in the vast majority of cases. In some areas, it was also possible for complainants to speak to an Asian female officer, if requested. In one officer's experience, listening to the needs of the woman early on made it more likely that the authorities would be able to progress to a criminal justice outcome.

\section{Not understanding cultural needs}


Another perception held by the women was that the police would not understand their individual cultural needs and, in particular, not appreciate the barriers facing many of them in terms of why they found it difficult not only to report violence but also to proceed to a prosecution. A number of women we interviewed expressed concerns about police understanding of the conducive context of sexual abuse in South Asian communities.

It's all, the more patriarchal society is, the more abusive it is, but you know, that's not something about [the] South Asian community; you're [they the police] saying our men are violent, because they're not. You know, our men are no more violent than any man in the West is and it's about putting that in context. They think South Asian[s] are monsters who are going out there trying to rape innocent white girls. I mean it's really difficult because it's, like, the police actually do hold these attitudes; as much as they say they don't, they do. They need to challenge their own behaviour; they need to challenge their own stereotypes. It's so engrained in their institution. I mean, the more I hear about the police, you know, more and more comes out about that institutional racism; they need to challenge that; they need to sort of believe in women and girls; they need to have, you know, more specially trained officers, who are adequately trained.

While this participant had a very poor opinion of the police and their understanding of the complex issues at play within South Asian communities, the police themselves believed that they did understand the complexity of the issues involved. When asked, for example, why victim-survivors did not report sexual violence to the police, many of the officers showed a clear understanding of the myriad reasons involved, with culture often being cited as the most prevalent. Officers understood that victim-survivors "would rather not involve the State" and that often such violence would be handled by "themselves in some way, shape or form.” One officer very clearly explained his view of the issues:

It goes to culture. What they're doing is . . the victim is vulnerable because of culture, not because of anything else. They're probably strong in every other aspect in their life, but their Achilles heel is their culture, just similar to a police officer, isn't it? If a police officer's on drugs, buys drugs and [a] drugs supplier says, 'I'm going to show your chief constable unless you start getting me intelligence from . . .' It's the 
offender identifying the vulnerability, taking advantage, exploiting that vulnerability and I do think for certain communities, including the Asian, their culture, their tight knit family background, almost the Victorian ethos, is their Achilles heel.

Another officer succinctly explained how the South Asian community had a "culture of silence” when it came to any form of intimate partner violence.

Although some officers had only a basic understanding of the cultural needs of the South Asian communities, others displayed a deeper level of understanding in terms of their appreciation of the concepts of honour and shame. Honour (izzat in Urdu) is arguably one of the most significant facets of South Asian culture and it is generally seen to reside in the bodies of women (Coomaraswamy 2005). In honour-based societies, the husband is defined as the head of the family and the defender of its honour. As such, men are expected to protect their family, particularly its female members, against any behaviour the community might view as dishonourable or humiliating (Cowburn, Gill and Harrison, 2015). If something dishonourable or humiliating occurs, honour is replaced by shame (sharam in Urdu). ${ }^{4}$ 
As one officer explained: "issues of honour . . . and shame ... are ingrained deeply ... in the South Asian communities [and] are significant barriers.” Of these two concepts, shame, is arguably the greater barrier when it comes to reporting, because admitting violence is taking place - most especially by bringing the problem outside of the family and community would convey shame onto the woman involved. In contrast to Western practices, this shame is placed on the woman rather than the perpetrator. One of the officers showed awareness of this difference when he said:

If we went to our families and said this has happened to us, it would be as horrific for them as it would be for us but there would be certainly no intention on my parents' or my family's part to say 'You can't go to the police because it's gonna look bad on the family' and all the other raft of issues that come with it. But it's probably only since I've worked here that I actually get it, now that I actually understand the shame that they perceive.

In addition to the shame placed on women simply for talking to the authorities, many of the officers also understood how, on the basis that "they're very modest, private women”, it would be seen as dishonourable for them to even discuss what had happened to them. In general, therefore, police officers appeared to understand how intimate partner sexual abuse in some South Asian communities was being "hidden within family culture” where “everything’s covered up.”

\section{Training}

Arguably, understanding of a community comes from either being a part of it or from training. Although some of the officers we spoke to were of South Asian descent, the vast majority of the officers consulted in this research came from non-Asian backgrounds. Nevertheless, only one of the four police areas evaluated appeared to have a sound training process in place with regard to issues specifically affecting South Asian communities. As previously mentioned, given that all four areas included high numbers of people from SouthAsian communities, this finding was, arguably, somewhat surprising. When officers from the other three areas were asked about training, their responses included: 
They will have had diversity training, but it's going to be pretty basic diversity training. You know, it's not going to be in depth and, again, until the demographics of the police service completely reflects what the communities [are] . . . we're always going to probably have that shortfall (Area One).

With regards to the issues that they may face because of the South Asian community and the type of homes that they are going into, there's obviously diversity training that they do as part of their initial course and that's about it if I'm honest (Area Two).

Regarding the third area, interwoven comments came from two officers:

Officer 1: We used to get diversity training. Does that still happen? I don’t even know if it still happens.

Officer 2: I think you get it when you join but I don't think you kind of have to keep redoing it. Once you've had your initial kind of training, that's it really though, isn't it?

Officer 1: We've not had any for years because once you've considered that you've had your training that's it.

Officer 2: We don't have a specific day set aside where you get training and, you know, you're going to be trained today in what, you know, how to deal literally with that side of things, but I think it is all very much part of the training package full stop because the whole awareness side of things has massively moved on.

When asked whether more training was required, particularly in terms of issues around South Asian culture, one officer agreed this training was essential: "I think that's the bit that we miss ... You get a little bit [in diversity training] but you won't get a great deal.” Another accepted that "We probably do need to invest more for that [good] level of understanding."

As previously highlighted, however, one police area was not only training its staff in detail but also trying to share this best practice with other neighbouring forces through the holding of a regional conference. The impetus for and emphasis on diversity training had, however, come from the bottom up rather than the top down. Moreover, although now endorsed by higher officers, one explained how he had undertaken a lot of research involving the reading of books and reports. Another pointed to knowledge gained from being practically involved 
with the issues: "It has been [about being] hands-on and wanting to know. And we want to know.” These officers had initially arranged for a South Asian women's charity to give a talk explaining the concepts of honour, shame and honour-based violence (HBV) to their officers to enable them to fully understand the needs of women from South Asian backgrounds. As acknowledged by one of the officers: “Diversity training wouldn’t help us with HBV.” They are now replicating this training and also extending it to front-line officers to ensure that, as first responders to a complaint, they know what signs to pick up on when going into women's homes and also that they are aware of the "dos and don'ts.” Both officers thought this breadth of training was essential in ensuring the protection of women from the outset. These officers were also asked why they had stressed the importance of police officers' having this level of training from the very beginning. One explained it was impossible to work with South Asian women unless such issues were understood. The other stated: "At the end of the day these women, if they're brave enough to come to us, then we've got to step up to the mark and make sure they're kept safe.”

It is important that the specialist police officers who deal with cases involving so-called HBV and sexual abuse in South Asian communities are regularly trained in how to handle such cases. The idea underlying such training should be to facilitate the gradual erosion over time of harmful views and behaviour (e.g. in terms of upholding family honour) which damage and disadvantage women and their family members, and to ensure that female victims are provided with appropriate, sustainable remedies, while simultaneously according respect to non-harmful cultural practices. Thus, such training would be expected to be conducted with care and sensitivity and should include a contextual understanding that HBV is usually a form of gender-based violence and is deeply damaging to women and girls.

\section{Police practice}

As previously mentioned, the women in the study cited other perceptions about the police; these included a belief that the police would side with the males in their family, that they would not be believed and that, even if they were taken seriously, the police would fail to act on their complaints. For example, one interviewee, Rabina, who suffered sexual abuse by her older brother throughout most of her childhood failed to report it, until eventually her sibling's violent physical attack against her during her adolescence prompted her for the first 
time to inform the police about the abuse. She observed, of the male police officer who attended:

He just seemed to, like, not to care one bit, and he kind of believed what my brother was saying. I think it was because he had this false old woman witness. I told the police my brother was beating me up, and I explained to him what had happened. And he was, like, "Well no, he’s got a witness to say that you burst in..."

One of the longstanding criticisms of the police levelled by a number of the victims-survivors of sexual abuse interviewed for this study relates to police attitudes. These interviewees presented evidence from their own experience that officers on the ground are still often ignorant about this form of violence and so may stereotype both the victims and abusers, resulting in inadequate service responses. Many of the victims-survivors argued that receiving an effective response from the police feels like 'a postcode lottery.' These perceptions were, therefore, tested by examining exactly which services and provisions were available to women from South Asian communities. Exploring such resources also made it possible to learn more about the attitudes and motivations of police officers towards wouldbe complainants.

When the officers were asked what services were specifically available for South Asian women, many initially said that such women were not treated any differently from any other complainant. However, as the conversation continued, it became evident that this was not strictly true. As previously mentioned, all four areas had attempted to put measures in place to provide a female officer when one was requested and, in some instances, this provision extended to requests for South Asian female officers. All areas acknowledged, however, that it was not always possible to provide a female officer, especially when it was a "response officer who made the initial house call." Linking this point to the general awareness displayed regarding the cultural needs of South Asian women, some of the officers explained that one difference was that they possibly had to be more mindful of the home environment and the subsequent consequences of reporting: "If you've got somebody from a South Asian community, then I'd certainly think is there a HBV risk here?” One officer described being mindful of "intimidation . . . whether it's through family trying to sort of dissuade the victim from speaking with the police or continuing with the complaint.” Another summed up the thought process as follows: 
Even if we can go to the CPS and say that we want to charge today ... we still have to consider that the victim could be living with mother-in-law, father-in-law and extended family in the same house - what checks and measures have been put in place for her? Do we take her out and put her into secure accommodation? Is there an honour-based violence risk? Could they attempt to intimidate her, which they could because quite often what we'll find is that they are younger women; they are here on their own; they've got no family of their own here; it's very much reliant on husband and his family. Their family may be some distance away. If they speak to their families, you know, how does that look for their family back in India or wherever they might be, so there's massive pressures and it's not something that goes unnoticed.

The police were also fairly well aware of the third sector agencies in their areas that offer support to women who have been sexually abused. Although some abuse referrals came via such organisations, one officer explained that if the victim directly approached the police, the victim would be personally assured that her "health and wellbeing” would be safeguarded. Police engagement with other agencies also included referrals to refuges and, in some cases, to Asian-specific refuges, if requested. However, many of the officers indicated that some South Asian women preferred not to go to Asian-specific agencies for fear of their circumstances being somehow communicated to the community. Protecting those women was, therefore, considered a high priority by all the police areas. Even though many officers emphasised the role of the police as a law enforcement agency, many also stated that it was important for the woman involved to be supported, even if that support meant that a criminal justice route was not followed. As one explained:

You have to follow the victims. What we don't want to do is completely ostracise, distance the victim, because if there's further abuse, which invariably there will be, then where the victim had the previous confidence to go to [a/the] law enforcement agency, they no longer have that. It depends on what they want and we are very led by the victim.

Despite offering a wide range of services and using a victim-centred approach, some officers nevertheless accepted that more could be done. One spoke about the difficulties of witness protection, perceiving it as easier to relocate and resettle a white person in, for example, a 
small market town than it would be to relocate a woman from a South Asian background, thus acknowledging that such resettlement would be "a real big challenge" for such a complainant.

\section{The need to improve services}

While there have been a number of welcome criminal justice improvements in practice and policy, the majority of the women's NGOs interviewed still felt that some police officers demonstrate a lamentable ignorance about the causes and consequences of sexual violence in South Asian communities. These were, however, general comments and may not relate to the four police areas which are the focus of this article.

While the scant attention given to the issue of intimate partner sexual violence in terms of health, social, welfare and support provisions for victims remains worrying, opinion among women's NGOs regarding the overall efficacy of the British government's approach to gender-based violence against women in South Asian communities continues to be mixed (HMIC, 2015). Interviewees working with victims-survivors in this study identified the key current difficulties as revolving around a lack of funding for and investment in support services (a major concern identified by all interviewees from women's NGOs) and successive governments' focus on providing criminal justice responses without broad support and protection being offered to victims and those at risk. These challenges have led women's organisations to struggle to meet the needs of the women served by them. A more holistic approach is urgently needed. Many victims-survivors highlighted the importance of not just improving criminal justice initiatives, but also the need for properly resourced women's support projects, refuges and outreach services that work in conjunction with awarenessraising programmes and welfare measures. Significant work is needed within and alongside communities to encourage reporting of sexual violence and abuse, along with closer collaboration with and between specialist services tackling violence against women within South Asian communities. This joined-up approach would assist the police in terms of better understanding the dynamics of 'honour'. In particular, a co-ordinated approach would illuminate how this concept exerts psychological and physical control over victims - and how the wider family and community may be implicated in the abuse - while also unmasking the multiple barriers to reporting and the high level of risk facing victims who decide to approach the police. 


\section{Concluding remarks}

The fact that women who choose to remain in violent intimate relationships and/or family situations tend generally to be viewed as somehow lacking credibility is particularly problematic in relation to sexual abuse cases involving South Asian women (HMIC, 2015). Even though many of the officers interviewed for the empirical study which underpins this article did demonstrate an understanding of why victims-survivors from Pakistani, Bangladeshi, Indian and South Asian communities do not report sexual violence to the police, it was also evident that the majority of officers were reliant on training to aid their understanding of those communities. Police training in the area of violence towards women from South Asian communities is generally not ongoing. For such training to be effective it needs to be regularly revisited and improved. Additional training at present seems to be ad hoc and sporadic. This finding is of further significance, in part, because of the conditional and discretionary element of police protection offered; that is, the nature and extent of this protection depends on the individual police officer's perception of the incident(s) in question. While this flexibility is intended to provide the police with considerable room for manoeuvre so that they can choose the most appropriate response for specific situations, it has to be backed up by cultural understanding to be effective. As few police officers currently come from Britain’s South Asian ethnic communities, this understanding needs to be brought about through expert, in-depth, ongoing training.

Furthermore, although policing responses have assisted and improved the experiences of many victim-survivors of sexual violence, these measures remain insufficient and do not affect the vast majority of victims who do not report rape to the police. For that reason, we need to think more imaginatively about how to create new openings and opportunities that will encourage victim-survivors to engage with the criminal justice system, and ways to persuade those who currently do not report to do so. In contemplating ways forward, there is a need for more work with survivors of sexual violence in terms of emphasising the importance of changing cultural beliefs and attitudes of the police toward gender and sexual violence, as well as improving support in terms of victim-survivors' perceptions of the police. This type of work may go some way in addressing victim-survivor needs and current dissatisfaction with the formal justice system. An awareness of both gender and culture is needed so that those dealing with intimate partner sexual violence can better recognise the 
conditions which give rise to it in South Asian communities. This deeper understanding would bolster efforts to prevent the abuse and also facilitate the provision of aid to those victims of abuse who are often reluctant to come forward due to the risk of facing condemnation from their own communities.

\section{Notes}

1. The term 'intersectionality', coined by Crenshaw (1992), parallels other scholars' observations of the multifaceted nature of oppression such as 'double/triple jeopardy', 'multiple jeopardies', ‘multiple oppressions', ‘multiple consciousnesses' and 'racialised gender' (King, 1988). Collins (2000) also highlights the importance of considering interconnecting social structures and the influence of institutional power, particularly 'race', class, gender and sexuality, which shape people’s social location as well as their experienced and enacted identities.

2. In the UK, the term 'black and minority ethnic' (BME) is used to refer to members of the population who are of non-white descent. There is significant variability regarding race/ethnicity within the umbrella terms 'BME'. We use this term to describe people from a cultural or ethnic minority in the UK. This group is not homogenous and differences exist even between the members of the respective ethnic groups.

3. This project - The South Asian Community's Response to Sexual Offending was funded by the British Academy, grant number SG122150.

4. For more on the concepts of honour and shame, see Gill, A., Strange, C., Roberts, K. (2014). 'Honour' Killing and Violence: Theory, Policy and Practice, London: Palgrave Macmillan.

\section{References}

Anitha, S. (2008) Forgotten Women: Domestic Violence, Poverty and South Asian Women with No Recourse to Public Funds. Oxfam Publishing: Manchester.

Bhatti-Sinclair, K. (2011) Anti-Racist Practice in Social Work, Palgrave/Macmillan, Basingstoke.

Brah, A., Phoenix, A. (2013) Ain’t I A Woman? Revisiting Intersectionality, European Journal of Women's Studies, 20: 233-248 
Cowburn, M., Gill, A., Harrison, K. (2014) Speaking about sexual abuse in South Asian communities: Offenders, victims and the challenges of shame, Journal of Sexual Aggression, $21(1), 4-15$.

Crenshaw, K. (1992) Mapping the margins: intersectionality, identity politics, and violence against women of colour, Stanford Law Review, 43: 1241-1242.

Coomaraswamy, R. (2005) 'Violence against women and crimes of honour', in L. Welchman and S. Hossain (eds), Honour. Crimes, Paradigms and Violence against Women. London: Zed Books.

Donovan, C. and Hester, M. (2014) Domestic Violence and Sexuality-What's Love Got to do with It? Bristol: Policy Press.

Gilligan, P., Akhtar, S. (2006) Cultural barriers to the disclosure of child sexual abuse in Asian communities: Listening to what women say, British Journal of Social Work, 36 (8): 1361-1377.

Hester, M., Williamson, E., Regan, L., Coulter, M., Chantler, K., Gangoli, G., Davenport, R. and Green, L. (2012) Exploring the Service and Support Needs of Male, Lesbian, Gay, BiSexual and Transgendered and Black and Other Minority Ethnic Victims of Domestic and Sexual Violence, Bristol: University of Bristol.

Hohl, K. and Stanko, E. (2015) Complaints of rape and the criminal justice system: Fresh evidence on the attrition problem in England and Wales, European Journal of Criminology 12(3), pp. 324- 341.

Home Office (2015) Police workforce, England and Wales: 31 March 2015. Available at: https://www.gov.uk/government/publications/police-workforce-england-and-wales-31march-2015/police-workforce-england-and-wales-31-march-2015\#introduction, accessed 21 March 2016.

Jones, J. (2015) NGO briefing on violence against women and girls in the UK. Bristol: University of the West of England. Available from http://sigbi.org/assets/UK-NGO-brief-part1.pdf [last accessed 27 May 2016].

King, D. (1988) Multiple jeopardy, multiple consciousness: the context of a black feminist ideology, Signs, 14(1), pp. 42-72.

HMIC (2015) The depths of dishonour: Hidden voices and shameful crimes. Available: https://www.justiceinspectorates.gov.uk/hmic/wp-content/uploads/the-depths-ofdishonour.pdf, accessed 3 April 2016. 
Izzidien, S. (2008) I can't tell people what is happening at home': Domestic Abuse within South Asian Communities - The Specific Needs of Women, Children and Young People. NSPCC: London.

Quereshi, T., Berridge, D. and Wenman, H. (2000) Where to Turn? Family support for South Asian communities - A case study, Joseph Rowntree Foundation, National Children's Bureau: London.

Walby, S., Armstrong, J. and Strid, S. (2012) Intersectionality: multiple inequalities in social theory, Sociology, 46(2), pp. 224-240. 